\title{
Influence of initial hydration conditions of cement on the process and fracture parameters of hardened cement paste structure of different age
}

\author{
N. I. Makridin ${ }^{1,}$, I. N. Maksimova ${ }^{1, b *}$ and J. V. Polubarova ${ }^{1, c}$ \\ ${ }^{1}$ Penza State University of Architecture and Construction, Street Titov, 28, 440028 Penza, Russia \\ atechbeton@pguas.ru, ${ }^{b}$ maksimovain@mail.ru, ${ }^{c}$ polubarova_sm@mail.ru
}

\begin{abstract}
Keywords: Hardened cement paste, Strength, Acoustic emission, Stress intensity factor, Fracture energy of material.
\end{abstract}

Abstract. The experimentally obtained kinetic dependencies of the influence of super plasticizer on the fracture process and structural quality parameters of the compared series of the hardened cement paste samples are shown. Its analysis shows that modification of cement stone structure by superplastiticizer in quantity of $1 \%$ from cement mass at equal water - cement ratio leads, on the one hand, to the decrease of axial strength compression $\left(R_{c S}\right)$ in the examined time intervals, on the other hand, to the sound increase of structural crack resistance, coefficient of stress intensity $\left(K_{1 C}\right)$ at the age of 420 days and 18 years which is explained by the peculiarities of hydration hardening of cement binding at the change of hardening conditions in the presence of superplasticizing additive which make possible according to X-rayogram to conclude about the influence of crystal structuring degree, value of specific surface of appearing phases and density of dislocations in the structure on the process and parameters of cement stone destruction from the position of mechanics of materials destruction.

\section{Introduction}

According to the modern views, the strength enhancement of hardened cement paste and concrete obtained by using the plasticizers is caused not only by the reduction of water in concrete mix, and therefore it leads to the porosity contraction in the hardened cement paste. But also it is caused by the dispersion of the aggregate particles of cement, the change of electrical phenomena at the phase boundary of the cement particles and also by the conditions of hydration process, bringing to the formation of a higher content of gel component of hardened cement paste. According to V. G. Batrakov [1], chemical additives are technological problem solution of modern concrete and they can cardinally change molding properties of cement systems, density, homogeneity and strength of the matrix phase structure of the cement composites.

We have shown [2] the influence of concentration and the introduction of super plasticizer into the cement-water composition on submolecular heterogeneity of the hardened cement paste structure. By O. P. Mchedlov-Petrosyan [3], the amount of its $L_{d}$ mosaic units was determined by means of the ionization x-ray patterns of hardened cement paste in the age range from 28 days to 18 years. It allows to judge about the granulometric homogeneity of the structure of the formed phases, about the degree of ordering of the crystals, the specific surface area of the formed phases and about the dislocation density in the structure that can ultimately determine the strength of the hardened cement paste as the matrix concrete basis of increased strength. However, all these facts do not reveal the effect of super plasticizer on the process and fracture parameters of hardened cement paste from the standpoint of structural fracture mechanics of materials.

\section{Experiments}

This paper presents the results of experimental evaluation and identification of fracture process of hardened cement paste samples of type I according to GOST (State All-Union standard) 29167 
on the energy characterization of acoustic emission $\left(\sum E_{\mathrm{AE}}, \mathrm{V}^{2} / \mathrm{cm}^{2}\right)$, which was registered using acoustic emission device [4] in real time under non-equilibrium mechanical testing of prototypes.

For the manufacture of the hardened cement paste prototypes the plain sulphate-resistant Portland cement of normal consistency ( $24 \%$ ), M-400, by Volsk plant, was used in the study of influence of additive of super plasticizer on the fracture process and its disintegration parameters. Two series of samples of type I with size $4 \times 4 \times 16 \mathrm{~cm}$ were produced with $\mathrm{W} / \mathrm{C}=0,24$ (water-tocement ratio). This means that the control set of samples № 1 was prepared without super plasticizer (SP) C-3 and the other set of samples № 2 was made in dosage of $1 \%$ by weight of cement. The super plasticizer was pre-dissolved in the mixing water.

Molding of the samples was carried out on a laboratory vibratory platform with standard vibration parameters within 3-5 s. The molded samples were placed over water in a closed hydraulic tub. After curing for 17 hours, the samples were exposed to wet and heat processing in the laboratory, according to the mode: temperature rise lasted for 2 hours and isothermal curing lasted 8 hours at a temperature of $85-90{ }^{\circ} \mathrm{C}$. The natural cooling of the samples was in the curing room. Then, the samples were in natural laboratory conditions, where temperature and relative humidity vary seasonally, in the range of $8-24{ }^{\circ} \mathrm{C}$ and $56-90 \%$, respectively.

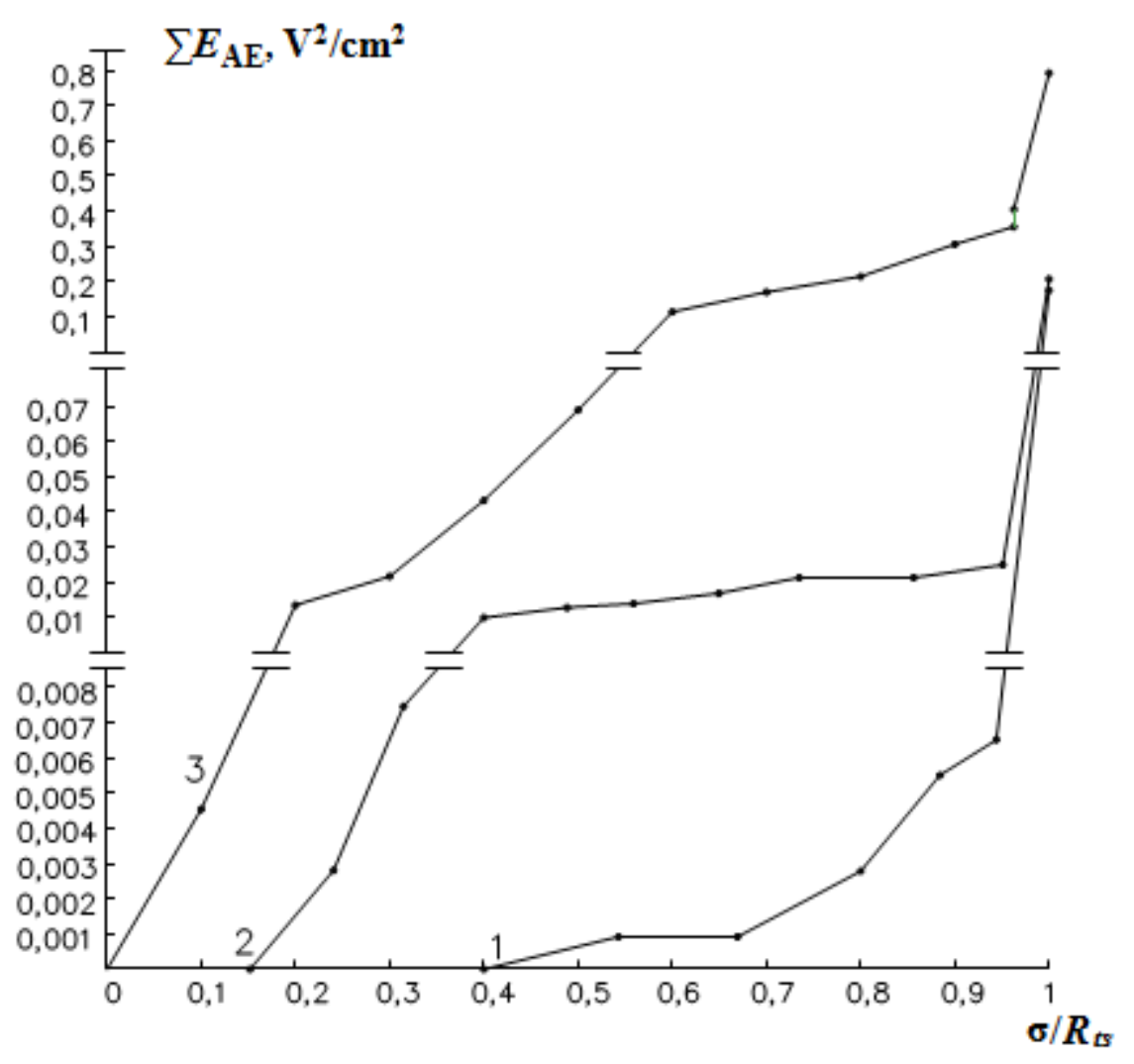

Fig. 1. The dependencies of integral energy of acoustic emission $\left(\sum E_{\mathrm{AE}}, \mathrm{V}^{2} / \mathrm{cm}^{2}\right)$ on the relative strain $\left(\sigma / R_{t s}\right)$ for the samples of hardened cement paste №1: 1 - at the age of 28 days; 2 - at the age of 420 days; 3 - at the age of 18 years

The kinetics of changing the physical and mechanical properties of hardened cement paste of the compared samples № 1 and № 2 was observed for 18 years. It should be noted that the assessment of the controlled parameters was conducted in the laboratory at a temperature of $(20 \pm 2){ }^{\circ} \mathrm{C}$ and relative humidity of 58-60\% during all the period of the testing.

In Fig. 1 and 2 the experimental kinetic dependencies $1-3$ of the total energy of acoustic emission (AE) in the curve of loading are shown. The experimental samples of the hardened cement 
paste of the type I under non-equilibrium mechanical testing at the age of 28 and 420 days and 18 years, respectively, are compared.

From the analysis of the dependences 1-3, it follows that with equal other conditions of recording of the integral energy of acoustic emission energy, AE intensity from the prototypes loading level at the age of 28 days is significantly lower than the intensity at the age of 420 days and, especially at the age of 18 years. That is, of course, due to a different degree of cement hydration. On the other hand, the total energy intensity of the AE of the prototypes of the type № 1 at the age of 18 years was two times higher than that of the samples № 2 at the same age. That reflects the characteristics of the hydration hardening of cement binder while changing the hardening conditions with the additive SP present.

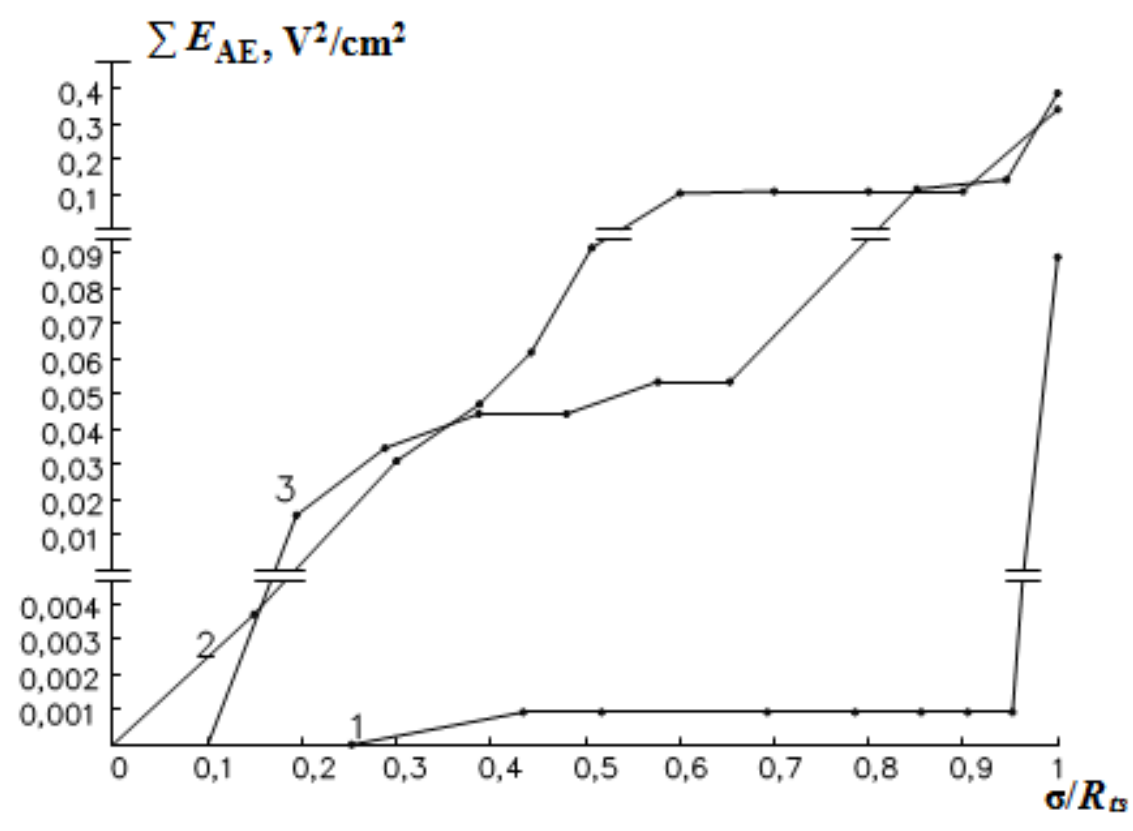

Fig. 2 The dependencies of integral energy of acoustic emission $\left(\sum E_{\mathrm{AE}}, \mathrm{V}^{2} / \mathrm{cm}^{2}\right)$ on the relative strain $\left(\sigma / \mathrm{R}_{\mathrm{ts}}\right)$ for the samples of hardened cement paste №2:

1 - at the age of 28 days; 2 - at the age of 420 days; 3 - at the age of 18 years

Previously [5], by x-ray diffraction studies of prototypes at the 18 age, it has been shown that activation of hydration processes due to the dispersion of binder particles takes place in cement system in the presence of SP, containing active functional groups. In parallel with this, the processes of change in the morphology of calcium hydrosilicates and hydrate recrystallization take place, which leads to a significant change of dispersion-crystallite structure, properties, and parameters of the mechanical behavior of cement materials.

\section{Calculations}

The analysis of the numerical values of the mechanical properties of the compared series in control period of hardening is given in the table. That allows us to conclude that the compressive strength $\left(R_{c s}\right)$ as well as the test and modified structures of cement stone has a tendency to increase. Samples of the first series showed an increase of $17.3 \%$ and the samples of the second series $19.9 \%$. The samples with SP during all periods of the tests showed lower values compared to the control samples.

The analysis of the tensile strength values in three-point bending $\left(R_{t s}\right)$ of the testable samples reflects a different tendency. The strength of the testable samples at the age of 28 days exceeds the 
strength of the samples $R_{t s}$ with SP $33.8 \%$, then the strength of the samples with SP at the age of 420 days rises by $4.9 \%$. Despite a slight decline of tensile strength values $\left(R_{t s}\right)$ at the age of 18 years, there was an excess of $R_{t s}$ of hardened cement paste samples with SP over the samples without SP and it was $22 \%$. Structural parameter of cracking resistance ( $K_{1 C}-$ stress intensity factor) showed similar changes on samples at the testable period of time. That reflects the impact of the dispersion-crystilline structure modification of hardened cement paste on the mechanism and the numerical values of the fracture parameter of structure under load $\left(\sum E_{\mathrm{AE}}\right)$ and also on the numerical values of strength and stress intensity factor $\left(R_{t s}\right.$ and $\left.K_{1 C}\right)$.

The numerical values of the total energy parameters of the acoustic emission in the fracture process of prototypes are correlated with the quality parameters of hardened cement paste, shown in the Table 1.

Table 1. Quality parameters of samples № 1 and № 2.

\begin{tabular}{|c|c|c|c|}
\hline \multirow{2}{*}{$\begin{array}{c}\text { Properties and quality } \\
\text { parameters of hardened } \\
\text { cement paste }\end{array}$} & \multicolumn{3}{|c|}{$\begin{array}{c}\text { Quality parameters of } \\
\text { testable samples at the age of }\end{array}$} \\
\cline { 2 - 4 } & 28 days & 420 days & 18 years \\
\hline$R_{c s}[\mathrm{MPa}]$ & 76,7 & 87,5 & 90,0 \\
\hline$R_{t s}[\mathrm{MPa}]$ & 5,19 & 6,38 & 5,35 \\
\hline$K_{1 C}\left[\mathrm{MPa} \cdot \mathrm{m}^{0,5}\right]$ & 0,51 & 0,626 & 0,525 \\
\hline$G_{C}\left[\mathrm{~J} \cdot \mathrm{m}^{-2}\right]$ & - & 85,6 & 115,6 \\
\hline$\sum E_{A E}\left[\mathrm{~V}^{2} \cdot \mathrm{cm}^{-2}\right]$ & 0,17 & 0,21 & 0,79 \\
\hline$R_{c s}[\mathrm{MPa}]$ & & Samples № 1 & 81,8 \\
\hline$R_{t s}[\mathrm{MPa}]$ & 68,2 & 74,5 & 6,53 \\
\hline$K_{1 C}\left[\mathrm{MPa} \cdot \mathrm{m}^{0,5}\right]$ & 3,88 & 6,69 & 0,641 \\
\hline$G_{C}\left[\mathrm{~J} \cdot \mathrm{m}^{-2}\right]$ & 0,381 & 0,656 & 122,7 \\
\hline$\sum E_{A E}\left[\mathrm{~V}^{2} \cdot \mathrm{cm}^{-2}\right]$ & - & 75,3 & 0,39 \\
\hline
\end{tabular}

\section{Conclusions}

Thus, the information obtained on the parameter $\sum E_{\mathrm{AE}}$ can be used as a basis of the fracture process identification of cement composite under the impact of short-term loading with sufficiently precise identification of the process. This process values reflect the influence of the S-3 dosage on the disperse-crystallite structure formation of hardened cement paste and its mechanical behavior under load. That allows to use the obtained information to improve the understanding of the fracture process and identifying the material parameters that determine its destruction viscosity. On this basis one can also implement a rational optimization of the structure and the technology of cement systems with increased cracking resistance.

At the same time, on the basis of integrated assessment of the mechanical dispersion-crystallite behaviour of the hardened cement paste structure, from the standpoint of structural mechanics of material fracture, in the time interval from of 28 days to 18 years, it is possible to formulate the conclusion that modification of cement paste structure at micro- and nanoscale with the super 
plasticizer S-3 in the same W/C ratio leads to ambiguous effects on mechanical behavior. On the one hand, it leads to the compressive strength reduction $\left(R_{c s}\right)$ at all stages of testing and on the other hand, as for the strength $\left(R_{t s}\right)$ and structural parameter of cracking resistance $\left(K_{1 C}\right)-$ the modification leads to the declining of values $R_{t s}$ and $K_{1 C}$ only in the initial testable age. And at the age of 420 days and 18 years, the mentioned values of the modified hardened cement paste structure are much higher than that of testable samples without the super plasticizer S-3.

Thus, the meaning of additives as a necessary part of modern concrete and technological methods increases with the increase of the influence on cement hydration and structuring, and concrete mixing features which require deep understanding of physical and chemical aspects of regulation and synthesis of disperse crystal structure and construction strength of cement stone.

In theory and practice, the authors think, the main problem in modification of cement systems by superplasticizers is to find out the connection between the parameters of cement stone destruction and the procedure of superplasticizer introduction and its quality in order to achieve the desired mechanical features of cement system and prognostication of production concrete with increased reliability with crack resistance and durability.

\section{References}

[1] V. G. Batrakov, Modified concrete. Theory and practice. 2nd edition, Stroyizdat. 1998, pp. 768.

[2] N. I. Makridin, V. N. Vernigorova, I. N. Maksimova, About the structure formation of cement stone, Modern problems of building materials. Part 1: Perspective directions in the theory and practice of mineral binders and materials on their basis. Academic readings of RAACS. Proceedings of International Conference. Samara. 1995, pp. 7-10.

[3] O. P. Mchedlov-Petrosyan, Chemistry of inorganic construction materials. 2nd edition. Revised and enlarged, Stroyizdat. 1988, pp. 304.

[4] N. I. Makridin, E. V. Korolev, I. N. Maksimova, Pattern formation and the structural strength of cement composites, MSUCE. 2013, pp. 152.

[5] N. I. Makridin, O. V. Tarakanov, I. N. Maksimova, I. A. Surov, The time factor in the formation of the phase composition of cement stone structure, Reg. Archit. Eng. 2 (2013) 26-31. 